\title{
Third-Order Improved Runge-Kutta Method for Solving Ordinary Differential Equation
}

\author{
Faranak Rabiei and Fudziah Ismail
}

\begin{abstract}
In this paper we constructed the sets of explicit third-order Improved Runge-Kutta (IRK) methods. The method used in two and three stage which indicated as the required number of function evaluations per step. The third-order IRK method in two-stage has a lower number of function evaluations than the classical third-order RK method while maintaining the same order of local accuracy. In three-stages, the new method is more accurate compared to the classical third-order RK method. The stability region of methods are given and numerical examples are presented to illustrate the efficiency and accuracy of the new methods.
\end{abstract}

Index Terms-Improved Runge-Kutta Methods, two-step runge-kutta methods, order conditions, stability region, ordinary differential equations.

\section{INTRODUCTION}

Consider the numerical solution of the initial value problem for the system of ordinary differential equation.

$$
\begin{aligned}
& y^{\prime}(x)=f(x, y(x)), \quad x \in\left[x_{0} X\right], \\
& y\left(x_{0}\right)=y_{0} .
\end{aligned}
$$

One of the most common method for solving numerically (1) is Runge-Kutta (RK) method. Most efforts to increase the order of RK method, have been accomplished by increasing the numberof Taylor's series terms used and thus the number of function evaluations. In third-order classical Runge-Kutta method (RK3) three number of function evaluations is required per step. Many authors have attempted to increase the efficiency of RK methods with a lower number of function evaluations required.

As a result, Goeken et.al [1] proposed a class of Runge-Kutta method with higher derivatives approximations for the third and fourth-order method. Xinyuan [2] presented a class of Runge-Kutta formulae of order three and four with reduced evaluations of function. Phohomsiri and Udwadia [3] constructed the Accelerated Runge-Kutta integration schemes for the third-order method using two functions evaluation per step. Udwadia and Farahani [4] developed the Accelerated Runge-Kutta methods for higher orders. However most of the presented methods are obtained for the autonomous system while the Improved Runge-kutta methods (IRK) can be used for autonomous as well as non-autonomous systems. Rabiei and Ismail [5] constructed the New Improved Runge-Kutta method with reduced number of function evaluations. The method proposed of

Manuscript received October 10, 2011; revised November 20, 2011.

F. Rabiei is with the Department of Mathematics, Faculty of Science, University Putra Malaysia (email: rabiei@math.upm.edu.my) order three with two stages. Rabiei et al [6] constructed the Improved Runge-Kutta method for solving ordinary differential equations. The order conditions of the methods up to order five were derived also the convergence and stability region of the methods were discussed. Rabiei and Ismail [7] developed the fifth-order Improved Runge-Kutta method for solving ordinary differential equations. The method used only five stages. Rabiei et al [8] proposed the numerical solution of ordinary differential equations using fifth-order Improved Runge- Kutta method .

In section 2 we presented the derivation of IRK3 with tow stages using the Taylor's series expansion. In section 3 we proposed the method with three-stages which will be denoted as IRK3-3. In section 4 the stability region of the methods are discussed and in the last section, numerical examples are carried out and performance of the new method is compared with the classical RK2 and RK3 methods.

\section{THIRD ORDER METHOD WITH TwO-STAGES (IRK3)}

In two-stages $(s=2)$, the general form of IRK3 can be written as:

$$
\begin{gathered}
y_{n+1}=y_{n}+h\left(b_{1} k_{1}-b_{-1} k_{-1}+b_{2}\left(k_{2}-k_{-2}\right)\right), \\
k_{1}=f\left(x_{n}, y_{n}\right), \\
k_{-1}=f\left(x_{n-1}, y_{n-1}\right), \\
k_{2}=f\left(x_{n}+c_{2} h, y_{n}+h a_{21} k_{1}\right), \\
k_{-2}=f\left(x_{n-1}+c_{2} h, y_{n-1}+h a_{21} k_{-1}\right) .
\end{gathered}
$$

where $0 \leq c_{2} \leq 1$. In the derivation of the method we will use $c_{i}=\sum_{j}^{i-1} a_{i j}$; which is called the row sum condition of RK method, so here we have $c_{2}=a_{21}$.

To determine the coefficients of method given by (2), the IRK method expression (2) is expanded using the Taylor's series expansion. After some algebraic simplifications this expansion is equated to the true solution that is given by Taylor's series expansion. This result will be in the system of nonlinear algebraic equations which is denoted as order conditions. Finally we tried to solve as many order conditions as possible because the highest power of $h$ for which all of the order equations are satisfied is the order of resulting IRK method. A great deal of algebraic and numeric calculations is required for the above processes which were mainly performed using Maple.

Consider equations:

$$
\begin{gathered}
y^{\prime}=f(x, y)=f, \\
y^{\prime \prime}=f_{x}+f f_{y}, \\
y^{\prime \prime}=f_{x x}+2 f_{x y}+f_{y y} f^{2}+f_{y}\left(f_{x}+f f_{y}\right) .
\end{gathered}
$$


The values of $y^{\prime}(x), y^{\prime \prime}(x), \ldots$ are obtained by substituting, $x=x_{n}$. The Taylor's series expansion of $y\left(x_{n}+h\right)$ is

$$
\begin{gathered}
y_{n+1}=y\left(x_{n}+h\right) \\
=y\left(x_{n}\right)+h y^{\prime}\left(x_{n}\right)+\frac{h^{2}}{2 !} y^{\prime \prime}\left(x_{n}\right) \\
+\frac{h^{3}}{3 !} y^{\prime \prime \prime}\left(x_{n}\right)+O\left(h^{4}\right) .
\end{gathered}
$$

Substituting (3) into (4) we have

$$
\begin{aligned}
y_{n+1}= & y_{n}+h f+\frac{h^{2}}{2 !}\left(f_{x}+f f_{y}\right) \\
& +\frac{h^{3}}{6}\left(f_{x x}+2 f_{x y}+f_{y y} f^{2}+f_{y}\left(f_{x}+f f_{y}\right)\right) \\
& +O\left(h^{4}\right) .
\end{aligned}
$$

Define $F=f_{x}+f f_{y}$ and $G=f_{x x}+2 f_{x y}+f_{y y} f^{2}$; thus, giving

$$
y^{\prime \prime}=F, \quad y^{\prime \prime}=G+f_{y} F .
$$

After simplifying, can be written (5) as follows

$$
y_{n+1}-y_{n}=h f+\frac{h^{2}}{2} F+\frac{h^{3}}{6}\left(G+f_{y} F\right)+O\left(h^{4}\right) \text {. }
$$

Now, by using the Taylor's series expansion of $k_{1}, k_{2}, k_{-1}$ and $k_{-2}$ which are used in (2) we have

$$
\begin{gathered}
k_{1}=f \\
k_{-1}=f-h F+\frac{h^{2}}{2}\left(G+f_{y} F\right)+O\left(h^{3}\right), \\
k_{2}=f+h c_{2} F+\frac{h^{2}}{2}\left(c_{2}^{2} G\right)+O\left(h^{3}\right), \\
k_{-2}=f-h\left(1-c_{2}\right) F+\frac{h^{2}}{2}\left(\left(1-c_{2}\right)^{2} G\right. \\
\left.+\left(1-2 c_{2}\right) f_{y} F\right)+O\left(h^{3}\right) .
\end{gathered}
$$

Substituting the above formulas in (2) we obtain

$$
\begin{gathered}
y_{n+1}-y_{n}=h\left(b_{1}-b_{-1}\right) f+h^{2}\left(b_{-1}+b_{2}\right) F \\
+\frac{h^{3}}{2}\left(-b_{-1}-\left(1-2 c_{2}\right) b_{2}\right)\left(G+f_{y} F\right)+O\left(h^{4}\right) .
\end{gathered}
$$

Comparing (8) with (6) we obtained the following order conditions

$$
\begin{aligned}
& b_{1}-b_{-1}=1, \\
& b_{-1}+b_{2}=\frac{1}{2},
\end{aligned}
$$

$$
b_{2} c_{2}=\frac{5}{12}
$$

By satisfying the above order equations, it is possible to achieve the third-order method with two functions evaluation per step. Here, we solved the order conditions (9) - (11) in terms of $b_{-1}, b_{1}, b_{2}$ and choose $c_{2}$ as a free parameter. In table (I) we choose $c_{2}=\frac{4}{5}$ and $\frac{1}{2}$ which leads to two different sets of coefficients for IRK3.

\begin{tabular}{ccc}
\multicolumn{3}{c}{ TABEL I: IRK3 PARAMETERS SETS } \\
\hline Coefficient & Set1 & Set2 \\
\hline$c_{2}$ & $\frac{4}{5}$ & $\frac{1}{2}$ \\
$a_{21}$ & $\frac{4}{5}$ & $\frac{1}{2}$ \\
$b_{-1}$ & $\frac{-1}{48}$ & $\frac{-1}{3}$ \\
$b_{1}$ & $\frac{47}{48}$ & $\frac{2}{3}$ \\
$b_{2}$ & $\frac{25}{48}$ & $\frac{5}{6}$ \\
\hline
\end{tabular}

III. THIRD ORDER METHOD WITH THREE-STAGES (IRK3-3)

In three-stages $(s=3)$, the general form of IRK 3 is as follows:

$$
\begin{gathered}
y_{n+1}=y_{n}+h\left(b_{1} k_{1}-b_{-1} k_{-1}+b_{2}\left(k_{2}-k_{-2}\right)\right), \\
+b_{3}\left(k_{3}-k_{-3}\right), \\
k_{i}=f\left(x_{n}+c_{i} h, y_{n}+h \sum_{j=1}^{i-1} a_{i j} k_{j}\right), \\
k_{-i}=f\left(x_{n-1}+c_{i} h, y_{n-1}+h \sum_{j=1}^{i-1} a_{i j} k_{-j}\right) .
\end{gathered}
$$

For $i=1,2,3$ and $c_{1}=0, c_{2}, c_{3} \in\left[\begin{array}{ll}0 & 1\end{array}\right]$. Also we considered

$$
\begin{gathered}
c_{2}=a_{21}, \\
c_{3}=a_{31}+a_{32} .
\end{gathered}
$$

Using the Taylor's series expansion in section 2, we obtained the following order conditions for IRK3-3:

$$
\begin{aligned}
& b_{1}-b_{-1}=1, \\
& b_{-1}+b_{2}+b_{3}=\frac{1}{2}, \\
& b_{2} c_{2}+b_{3} c_{3}=\frac{5}{12} .
\end{aligned}
$$

By satisfying order equations (13)-(15), we obtained the third-order method with three function evaluations per step which we will be noted as IRK3-3. In Table II we presented the two sets of coefficients of IRK3-3. 
TABEL II : IRK3-3 PARAMETERS SETS

\begin{tabular}{ccc}
\hline Coefficient & Set1 & Set2 \\
\hline$c_{2}$ & $\frac{1}{3}$ & $\frac{1}{2}$ \\
$c_{3}$ & $\frac{2}{3}$ & 1 \\
$a_{21}$ & $\frac{1}{3}$ & $\frac{1}{2}$ \\
$a_{31}$ & $\frac{2}{21}$ & $\frac{-1}{3}$ \\
$a_{32}$ & $\frac{4}{7}$ & $\frac{4}{3}$ \\
$b_{-1}$ & $\frac{1}{8}$ & $\frac{-1}{12}$ \\
$b_{1}$ & $\frac{9}{8}$ & $\frac{11}{12}$ \\
$b_{2}$ & $\frac{-1}{2}$ & $\frac{1}{3}$ \\
$b_{3}$ & $\frac{7}{4}$ & $\frac{1}{4}$ \\
& &
\end{tabular}

In the last section, numerical results of IRK3 and IRK3-3 are compared with Butcher's classical second and third-order Runge-Kutta method [9] which are denoted as RK2 and RK3 in the Table III.

TABEL III: BUTCHER'S RK2 AND RK3 PARAMETERS

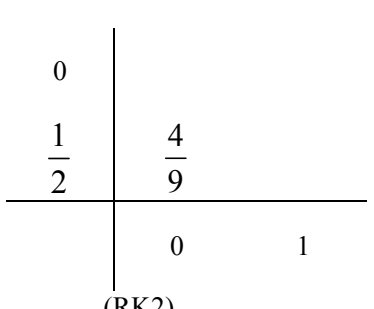

(RK2)

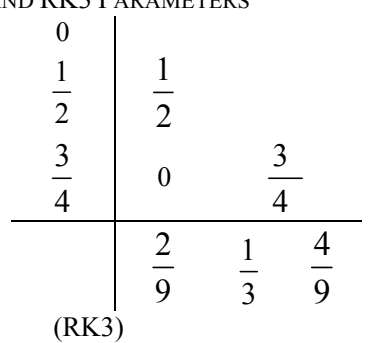

(RK3)

\section{Stability Analysis}

Generally, to define the stability region of the method we applied the test problem $y_{0}=\lambda y$, where $\lambda$ is a complex number. Here, by applying the test problem to (2) we have

$$
\begin{gathered}
y^{\prime}=\lambda y, \\
k_{1}=\lambda y_{n}, \\
k_{-1}=\lambda y_{n-1}, \\
k_{2}=\lambda\left(1+\lambda h a_{21}\right) y_{n}, \\
k_{-2}=\lambda\left(1+\lambda h a_{21}\right) y_{n-1} .
\end{gathered}
$$

Substituting all the above values in (2) we have

$$
\begin{aligned}
y_{n+1}= & \left(1+\bar{h}\left(b_{1}+b_{2}\left(1+\bar{h} a_{21}\right)\right)\right) y_{n} \\
& -\left(b_{-1}+b_{2}\left(1+\bar{h} a_{21}\right)\right) y_{n-1} .
\end{aligned}
$$

where $\bar{h}=\lambda h$. After substituting the order conditions given by (9)-(11) in (16) we obtained the following stability polynomial of IRK3

$$
\rho(\zeta, \bar{h})=\zeta^{2}-\left(\frac{5}{12} \bar{h}^{2}+\frac{3}{2} \bar{h}+1\right) \zeta+\frac{5}{12} \bar{h}^{2}+\frac{\bar{h}}{2}
$$

The three-stages method, using the same process the stability polynomial for fourth order method (IRK3-3) is

$$
\begin{aligned}
\rho(\zeta, \bar{h})=\zeta^{2} & -\left(\frac{1}{6} \bar{h}^{3}+\frac{5}{12} \bar{h}^{2}+\frac{3}{2} \bar{h}+1\right) \zeta \\
& +\frac{1}{6} \bar{h}^{3}+\frac{5}{12} \bar{h}^{2}+\frac{\bar{h}}{2} .
\end{aligned}
$$

Stability region of the methods is the set of the values of $\bar{h}$ such that all the roots of the stability polynomial are inside a unit circle. Here, the stability region of IRK3 which is plotted in Figure. 1 is done using Matlab.

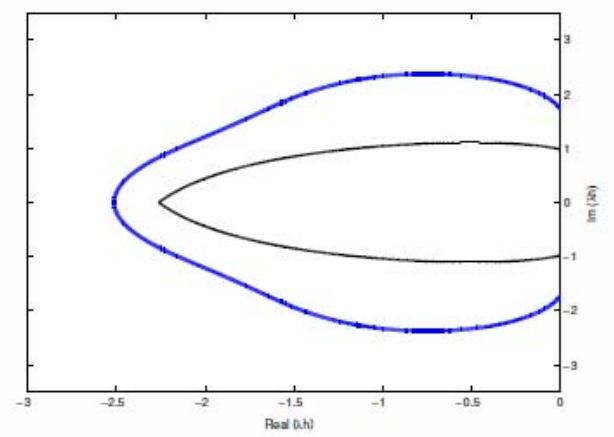

Fig. 1. Stability region of IRK3 (thin line) and RK3 (thick line) for

$$
\bar{h}=\lambda h \text {. }
$$

\section{NUMERICAL RESULTS}

In this section, we tested a standard set of initial value problems to show the efficiency and accuracy of the proposed methods. The exact solution $y(x)$ is used to estimate the global error as well as to approximate starting values of $y_{1}$ at the first step $\left[x_{0} x_{1}\right]$. The following problems are solved for $x$ $\in\left[\begin{array}{ll}0 & 10\end{array}\right]$.

Problem 1 (see [10])

$$
\begin{array}{cr}
y^{\prime}=y \cos (x), & y(0)=1, \\
\text { Exact solution: } & y(x)=e^{\sin (x)} .
\end{array}
$$

Problem 2 (see [10] )

$$
\begin{gathered}
y_{1}^{\prime}=-2 y_{1}+y_{2}+2 \sin (x), \\
y_{2}^{\prime}=y_{1}-2 y_{2}+2(\cos (x)-\sin (x)), \\
y_{1}(0)=2, \quad y_{2}(0)=3, \\
y_{1}(x)=2 e^{-x}+\sin (x), \\
y_{2}(x)=2 e^{-x}+\cos (x) .
\end{gathered}
$$

Exact solution: $y_{1}(x)=2 e^{-x}+\sin (x)$,

The maximum global error of the tested problems 1 and 2 against the step size are shown in Table IV and V. In Table VI, we compared the computational effort required for the classical Runge-kutta method to that required for the method presented. 
TABEL IV: MAXIMUM GLOBAL ERROR FOR PROBLEM1

\begin{tabular}{|c|c|c|c|c|c|c|}
\hline $\begin{array}{l}\text { Step } \\
\text { size }\end{array}$ & $\begin{array}{c}\text { IRK3 } \\
\text { Set1 }\end{array}$ & $\begin{array}{c}\text { IRK3 } \\
\text { Set2 }\end{array}$ & $\begin{array}{c}\text { IRK3-3 } \\
\text { set1 }\end{array}$ & $\begin{array}{c}\text { IRK3-3 } \\
\text { Set2 }\end{array}$ & RK2 & RK3 \\
\hline 0.5 & $\begin{array}{l}9.88 \\
\text { E-2 }\end{array}$ & $\begin{array}{l}7.46 \\
\text { E-3 }\end{array}$ & 4.22 E-3 & $1.18 \mathrm{E}-3$ & $\begin{array}{l}4.93 \\
\text { E-2 }\end{array}$ & $\begin{array}{c}2.02 \\
\text { E-2 }\end{array}$ \\
\hline 0.1 & $\begin{array}{l}8.28 \\
\text { E-4 }\end{array}$ & $\begin{array}{l}6.15 \\
E-4\end{array}$ & 8.79 E-6 & $2.26 \mathrm{E}-5$ & $\begin{array}{l}1.62 \\
\text { E-3 }\end{array}$ & $\begin{array}{l}1.90 \\
\text { E-4 }\end{array}$ \\
\hline 0.05 & $\begin{array}{l}1.02 \\
\text { E-4 }\end{array}$ & $\begin{array}{l}8.02 \\
\text { E-5 }\end{array}$ & $5.80 \mathrm{E}-7$ & 1.43 E-6 & $\begin{array}{l}3.91 \\
\text { E-4 }\end{array}$ & $\begin{array}{c}2.44 \\
\text { E-5 }\end{array}$ \\
\hline 0.01 & $\begin{array}{l}8.08 \\
\text { E-7 }\end{array}$ & $\begin{array}{l}6.53 \\
\text { E-7 }\end{array}$ & $\begin{array}{l}9.76 \\
\text { E-10 }\end{array}$ & 2.32 E-9 & $\begin{array}{l}1.52 \\
\text { E-5 }\end{array}$ & $\begin{array}{l}1.75 \\
\text { E-7 }\end{array}$ \\
\hline 0.005 & $\begin{array}{l}1.00 \\
\text { E-7 }\end{array}$ & $\begin{array}{l}7.90 \\
\text { E-8 }\end{array}$ & $\begin{array}{l}3.13 \\
\text { E-11 }\end{array}$ & $\begin{array}{l}1.45 \\
\text { E-10 }\end{array}$ & $\begin{array}{c}3.79 \\
\text { E-6 }\end{array}$ & $\begin{array}{c}2.43 \\
\text { E- } 8\end{array}$ \\
\hline
\end{tabular}

TABEL V: MAXIMUM GLOBAL ERROR FOR PROBLEM2

\begin{tabular}{|c|c|c|c|c|c|c|}
\hline $\begin{array}{l}\text { Step } \\
\text { size }\end{array}$ & $\begin{array}{l}\text { IRK3 } \\
\text { Set1 }\end{array}$ & $\begin{array}{c}\text { IRK3 } \\
\text { Set2 }\end{array}$ & $\begin{array}{c}\text { IRK3-3 } \\
\text { set1 }\end{array}$ & $\begin{array}{c}\text { IRK3-3 } \\
\text { Set2 }\end{array}$ & RK2 & RK3 \\
\hline 0.5 & $\begin{array}{l}3.73 \\
E-2\end{array}$ & $\begin{array}{l}3.04 \\
\text { E-2 }\end{array}$ & $4.79 \mathrm{E}-2$ & $8.21 \mathrm{E}-2$ & $\begin{array}{l}7.44 \\
\text { E-2 }\end{array}$ & $\begin{array}{l}1.88 \\
\mathrm{E}-2\end{array}$ \\
\hline 0.1 & $\begin{array}{l}2.42 \\
\text { E-4 }\end{array}$ & $\begin{array}{r}2.22 \\
\text { E-4 }\end{array}$ & 9.28 E-6 & $1.20 \mathrm{E}-5$ & $\begin{array}{l}1.60 \\
E-3\end{array}$ & $\begin{array}{l}1.07 \\
\text { E-4 }\end{array}$ \\
\hline 0.05 & $\begin{array}{l}3.05 \\
E-5\end{array}$ & $\begin{array}{c}2.79 \\
\text { E-5 }\end{array}$ & $5.80 \mathrm{E}-7$ & 7.56 E-7 & $\begin{array}{l}3.77 \\
\text { E-4 }\end{array}$ & $\begin{array}{l}1.25 \\
\text { E-5 }\end{array}$ \\
\hline 0.01 & $\begin{array}{l}2.45 \\
E-7\end{array}$ & $\begin{array}{l}2.25 \\
\text { E-7 }\end{array}$ & $\begin{array}{l}9.30 \\
\text { E-10 }\end{array}$ & $1.21 \mathrm{E}-9$ & $\begin{array}{l}1.44 \\
E-5\end{array}$ & $\begin{array}{l}4.53 \\
\text { E-7 }\end{array}$ \\
\hline 0.005 & $\begin{array}{l}3.07 \\
\text { E- } 8\end{array}$ & $\begin{array}{c}2.81 \\
\mathrm{E}-8\end{array}$ & $\begin{array}{l}5.82 \\
\text { E-11 }\end{array}$ & $\begin{array}{l}7.58 \\
\text { E-11 }\end{array}$ & $\begin{array}{c}3.59 \\
\text { E-6 }\end{array}$ & $\begin{array}{l}1.18 \\
\text { E- } 8\end{array}$ \\
\hline
\end{tabular}

TABEL VI: SUMMARY OF ORDER AND NUMBER OF FUNCTION EVALUATIONS FOR IRK AND RK METHOD PER STEP

\begin{tabular}{ccccc}
\hline & IRK3 & IRK3-3 & RK2 & RK3 \\
\hline Order of method & 3 & 3 & 2 & 3 \\
No function evaluations & 2 & 3 & 2 & 3
\end{tabular}

\section{CONCLUSION}

From tables IV and V we obtain that IRK3 has a lower number of function evaluations than RK3 method while maintaining the same order of local accuracy and IRK3-3 is more accurate compared with the classical RK3 method. In conclusion, third order improved Runge-Kutta methods, have been developed for numerical integration of first order ordinary differential equations. They are almost two-step in nature and they are computationally more efficient and produced smaller errors compared to the existing Runge-Kutta methods of the same order.

\section{REFERENCES}

[1] D. Goeken and O. Johnson, "Runge-Kutta with higher order erivative approximations," Appl. Numer. Math, vol. 34, pp. 207-218, 2000.

[2] W. Xinyuan, "A class of Runge-Kutta formulae of order three and four with reduced evaluations of function," Appl. Math. Comput, vol. 146, pp. 417-432, 2003

[3] P. Phohomsiri and F. E. Udwadia, "Acceleration of Runge-Kutta integeration schemes," Discrit. Dynamic. Nature. Soci. vol. 2, pp. 307-314, 2004.

[4] F. E. Udwadia and A. Farahani, "Accelerated Runge- Kutta methods," Discrit. Dynamic. Nature. Soci. 2008, doi:10.1155/2008/790619, 2008

[5] F. Rabiei and F. Ismail, "New Improved Runge- Kutta method with reducing number of function evaluation," ASME Press (2011), ISSN:9780791859797, DOI: 10.1115/1.859797. paper14

[6] F. Rabiei, F. Ismail, M. Suleiman, and N. Arifin, "Improved Runge-Kutta method for solving ordinary differential equation," Journal of Applied Mathematics, submitted 2011.

[7] F. Rabiei and F. Ismail, "Fifth-order Improved Runge-Kutta method for solving ordinary differential equation," Proceeding of WSEAS Conference, Penang, Malaysia, ISBN: 978-1- 61804-039-8, 2011, pp. 129-133.

[8] F. Rabiei and F. Ismail, "Numerical solution ofordinary differential equation using fifth-order Improved Runge-Kutta method," International Journal of Applied Applied Mathematics and Informatics, Submitted 2011.

[9] J. C. Butcher, "On Runge-Kutta processes of highh order," J. Australian. Math. Soci. vol.4, pp.179- 194, 1964.

[10] L. F. Shampine, "Numerical solution of ordinary differential equations," Chapman and Hall, New York, NY, USA, 1994.

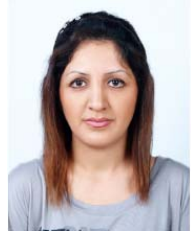

Faranak Rabiei was born on July 10 1982. She studied in Applied Mathematics for bachelor and Master degrees from Iran, she is $\mathrm{PhD}$ student from Department of Mathematics, Universiti Putra Malaysia. She is research assistant with the grant scholarship from Universiti Putra Malaysia. 